The World of Learning, 1954

Fifth edition. Pp. xii +1030 . (London: Europa Publications, Limited, 1954.) 100s. net.

Triter HE fourth edition of the "World of Learning" was published in 1947, and though it was very useful at the time to have this reference book so soon after the Second World War, it was not really so valuable as it at first sight seemed, in that the information relating to a number of countries that had been devastated by the War was not up to date. The new fifth edition, besides being as up to date as such a compilation as this can be, is a good deal enlarged; in particular, it opens with a new section on Unesco, giving its origins, aims, functions and organization as well as an account of its recent activities, and this is followed by a list of the principal international scientific organizations, with brief statements of their objects and the names of their main officials.

The rest of the book follows the plan of the previous edition. It is divided alphabetically (by English name) into the various countries of the world, and, where the entries for a country are sufficiently numerous, a contents list is given. The arrangement of entries for Great Britain gives an idea of the range of institutions, etc., covered : learned societies and professional associations; research institutes; libraries; museums and art galleries; universities and university colleges; centres for adult and technical education; schools of art, music and dramatic art; and educational trusts. Naturally, the range of headings varies somewhat from country to country. In general, the entry for each institution contains its address, the names of the leading officials and the date of foundation, and for each university a complete list of all the professors is given. Where applicable, the titles of publications issued by the body concerned are listed. A useful section of the book is that on the U.S.S.R., which is twenty-nine pages long; no universities are quoted, but a very full list of the numerous higher educational institu. tions and research establishments in the U.S.S.R. is given.

The book ends with a fifty-four page index of institutions, with more than two hundred entries per page. There is no name index. Other reference books exist covering universities and the more academic bodies to be found in the various countries of the world, and in this particular field the "World of Learning" is no more comprehensive, probably less so. But where it scores over the other books is in the very complete lists of non-university organizations such as learned societies, professional organizations, museums, etc., and for this it can be recommended.

\section{Public Health Engineering}

By Peter C. G. Isaac. (Spon's Civil Engineering Series.) Pp. xvii +277. (London: E. and F. N. Spon, Ltd., 1953.) 36s. net. 7 HE average member of the public in Britain is conception of the magnitude and complexity of the undertakings which deal with unhealthy products and supply him with pure water, 10-15 per cent of which he wastes. These and kindred activities are now classed under the heading of public health engineering, and this book under review is a welcome introduction to the subject. Nearly half of it is given up to water, its sources, collection, quality, analysis, treatment and distribution. Fifty pages are devoted to sewage and its purification-the ever-growing problem of river pollution is given a separate chapter -and the methods of treatment of trade wastes are illustrated by a number of specific examples. After discussion of refuse disposal and atmospheric pollution, the author concludes with a chapter on district heating, a subject which scarcely comes under the heading of sanitary engineering but one which is to be welcomed in view of its importance and the necessity of propaganda to induce the British public to revise its ideas on the subject of warming houses.

It is obviously impossible in one small volume to deal with all the subjects mentioned above in any detail, but the author has succeeded in giving an immense amount of information and, in addition, in presenting it in a readable and interesting manner. As the result of a stay in the United States, he has been able in many cases to quote American practice and to compare it with British, and there can be few people, even among sanitary experts, who will find nothing that is new to them. For the benefit of those wishing to go more deeply into a subject, numerous references are given at the end of each chapter. "Public Health Engineering" was written primarily for students and sanitary engineers; but it is to be hoped that it will attract the attention of a far larger circle of readers, since the matters dealt with are of vital importance to all. H. E. W.

\section{Table of Binomial Csefficients}

Prepared for the Mathematical Tables Committees of the British Association and the Royal Society, under the Editorship of J. C. P. Miller. (Royal Society Mathematical Tables-Vol. 3.) Pp. viii + 162. (Cambridge: At the University Press, 1954.) 35s. net.

HIS volume is actually the second of those to appear under Royal Society auspices as a consequence of the Cunningham Bequest of 1928, the first being E. H. Neville's "The Farey Series of Order 1025" (1950). Many establishments have co-operated in its production, including the National Physical Laboratory and the Royal Aircraft Establishment. As the computation of the tables was fairly simple, there is no need for a lengthy introduction. The basis of the calculations was the elementary recurrence formula of Pascal's triangle, and no further details or formulæ have been included.

All the tabulated values are exact, in order to meet the requirements of number theory (the primary object of the Cunningham Bequest). For values of $n$ up to and including 200 , every value of the binomial coefficient $\left(\begin{array}{l}n \\ r\end{array}\right)$ for each value of $r$ up to $\frac{1}{2} n$ is supplied, and the maximum coefficient (or pair of coefficients) appears in bold type. This tabulation, which forms the main part of the book, occupies a hundred and three pages in all. The remaining sixty pages are devoted to higher values of $n$, as far as 5,000 , with corresponding entries for small values of $r$ only, first up to 12 and then (as $n$ increases) 11,5 and finally 3 .

A page index, showing at a glance where any particular coefficient may be found, is supplied on p. 1 , and there is also a list of references to publications used or consulted. The whole book is beautifully produced, in the highest traditions of the Cambridge University Press.
J. H. Pearce 